\title{
Fluid Charging and Gas Reservoir Pressure Evolution of Longmaxi Formation Shale in Southeastern Chongqing
}

\author{
Cen Chen $\mathbb{D}^{1,2}$ Cheng Meng, ${ }^{1,2}$ Qidong You, ${ }^{3}$ Chao Luo,, ${ }^{1,2}$ Yang Chen, ${ }^{1,2}$ Zhuang Xiong, \\ and Pengjing $\mathrm{Xu}^{5}$
}

${ }^{1}$ Chongqing University of Science and Technology, Chongqing 401331, China

${ }^{2}$ Complex Oil and Gas Exploration and Development, Chongqing 401331, China

${ }^{3}$ Jiangsu Oilfield Company, SINOPEC, Yangzhou 225009, China

${ }^{4}$ China Petroleum Huabei Oilfield Exploration and Development Research Institute, Renqiu 062552, China

${ }^{5}$ Supervision Company, PetroChina Qinghai Oilfield, Dunhuang 570311, China

Correspondence should be addressed to Cen Chen; 22023927@qq.com

Received 3 September 2021; Accepted 18 November 2021; Published 4 February 2022

Academic Editor: Jianguo Zhang

Copyright (C) 2022 Cen Chen et al. This is an open access article distributed under the Creative Commons Attribution License, which permits unrestricted use, distribution, and reproduction in any medium, provided the original work is properly cited.

\begin{abstract}
Fluid charging and formation pressure evolution are of great significance for shale gas exploration and development. Taking the Longmaxi formation shale in southeast Chongqing as the research object, the fluid activity and pressure evolution process were studied by means of thin section observation, fluid inclusion analysis and testing, and basin numerical simulation. The results show that the area of the southeast of Chongqing, the Longmaxi formation of dike filling minerals, is mainly quartz vein and calcite part of the veins and arteries, and vein body captures the rich organic inclusions in minerals, sees fgas-liquid two-phase brine inclusions and methane inclusions, combining with the temperature and salinity of brine inclusions, and shows that the area has experienced two phases of oil and gas filling, the first period of gas-liquid fluid. The second stage is gas fluid. Combined with burial history and thermal maturation history, it is found that the filling time of oil and gas is late Cretaceous and Paleocene, respectively. In the Cretaceous, the pressure coefficient of Longmaxi formation reached the maximum value of 2.2 and remained above 1.5 overpressure after pressure unloading in the later period. In terms of the frequency of inclusions, the charging amount of the first stage is relatively large, and the charging time corresponds to the peak period of the palaeoformation pressure. At the same time, fluid charging can timely supplement the pressure after unloading, which is conducive to high and stable production of shale gas.
\end{abstract}

\section{Introduction}

Since 2008, China has explored multiple large marine facies shale gas fields in the southeast Chongqing area of Sichuan Basin (Figure 1), with shale gas resources exceeding $2.3 \times 10^{12} \mathrm{~m}^{3}$ (Sinopec, 2020); successful shale gas exploration has been achieved in the middle-shallow strata of the Lower Silurian Longmaxi formation (burial depth $2000 \mathrm{~m} \sim 3500 \mathrm{~m}$ ). At the same time, breakthroughs have been made in the exploration of deep shale gas $(3500 \mathrm{~m} \sim 4500 \mathrm{~m})$ in Yibin and Luzhou areas of Sichuan Basin $[1,2]$, making Sichuan Basin the most representative and potential area for marine shale gas exploration in south China [3-5].

\section{Geological Setting}

Under the action of the multicycle tectonic movement in the Sichuan Basin $[6,7]$, the Longmaxi formation in southeast Chongqing experienced the process of early deep burial and late strong uplift. Tectonism has two sides to the enrichment of shale gas $[8,9]$, which can not only improve the reservoir performance and form high-yield gas wells but also cause shale gas loss due to the failure of large faults and sealing conditions. The first member of Longmaxi formation is located in semi-deep-water to deep-water shelf facies, and high quality shale is developed with a thickness of $100 \mathrm{~m} \sim 130 \mathrm{~m}$. From the perspective of reservoir physical 


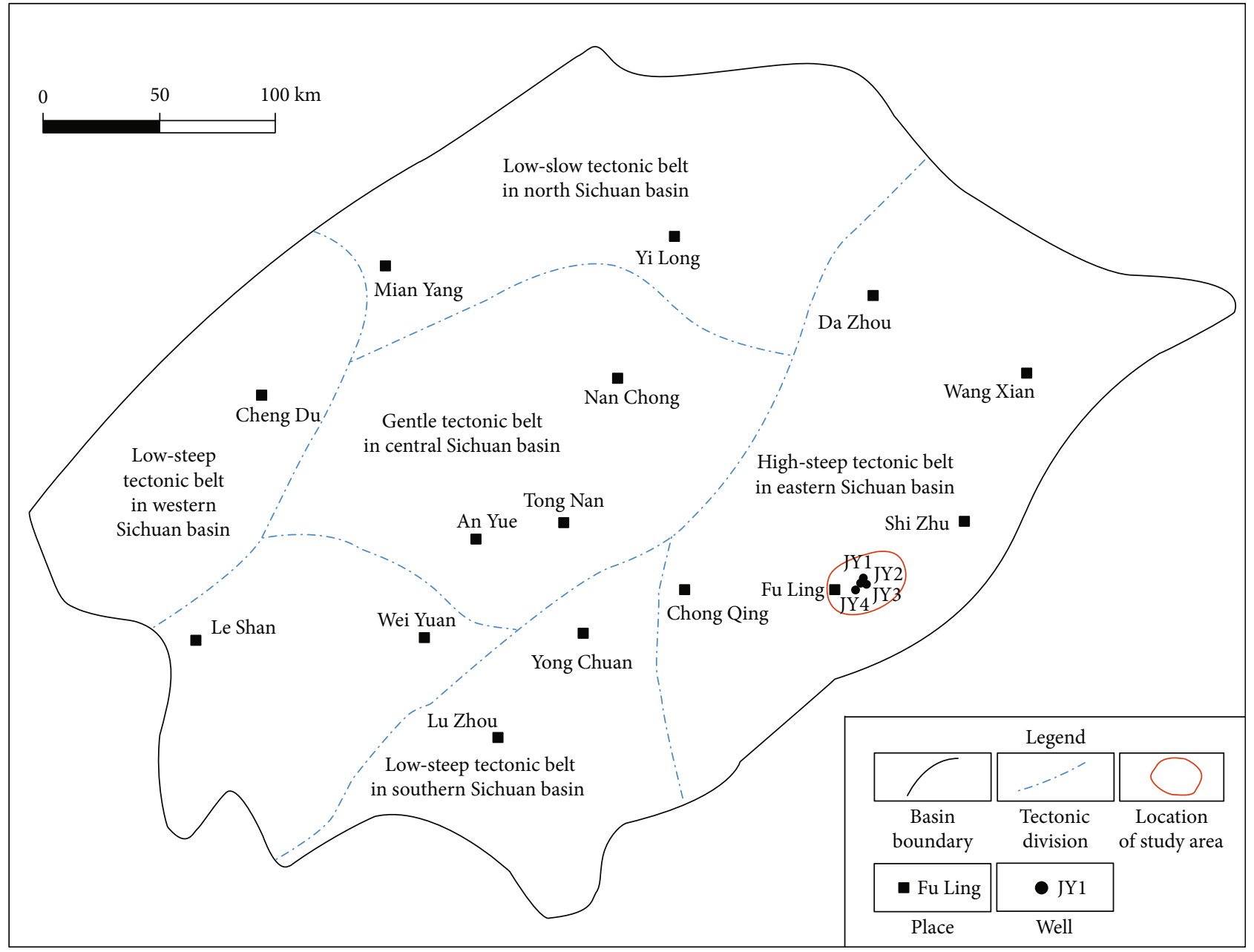

Figure 1: Tectonic location and block division of the study area in Sichuan Basin.

properties $[10,11]$, the high quality shale reservoirs in Longmaxi formation are mainly composed of organic pores and inorganic pores and fractures, with the characteristics of low porosity and ultralow permeability. Organic pores are the main reservoir space, and most of them are charged with fluid. The development degree of organic pores is the main factor restricting the occurrence of natural gas in shale. The organic matter types and maturity of Longmaxi formation shale are generally small, and the organic matter types are mainly saproli-type and partial humic saproli-type, although the current buried depth distribution is quite different. However, their equivalent vitrinite reflectance (Ro) was concentrated in the range of $2.3 \% \sim 3.1 \%[12-14]$ and had reached the mature stage. According to the exploration results of many shale gas fields in the basin, the high-yielding shale gas wells are mostly drilled in high-pressure gas reservoirs, such as JY1 well, whose pressure coefficient is still over 1.55 , and the gas production is positively correlated with the pressure coefficient (Figure 2). Therefore, to clarify the mechanism of shale gas fluid charging and preservation in the Longmaxi formation during the multistage tectonic evolution in southeast Chongqing, the controlling effect of formation pressure evolution on shale gas reservoirs can provide an important reference for shale gas exploration in other areas of Sichuan Basin [15].

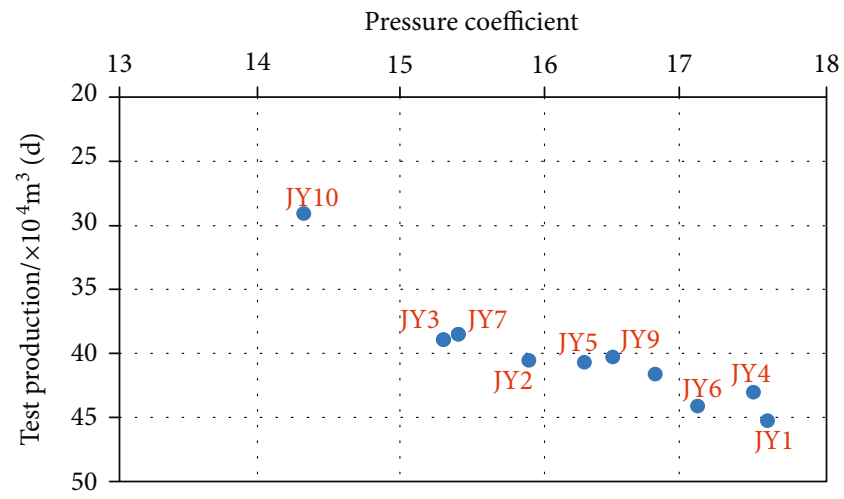

FIGURE 2: Relationship of pressure coefficient and test production (from Jianghan Oilfield Company).

\section{Materials and Analytical Methods}

In this paper, the Longmaxi formation shale in southeast Chongqing area is taken as the research object to study the fluid activity characteristics and pressure evolution process [16], determine the mineral filling sequence through thin 


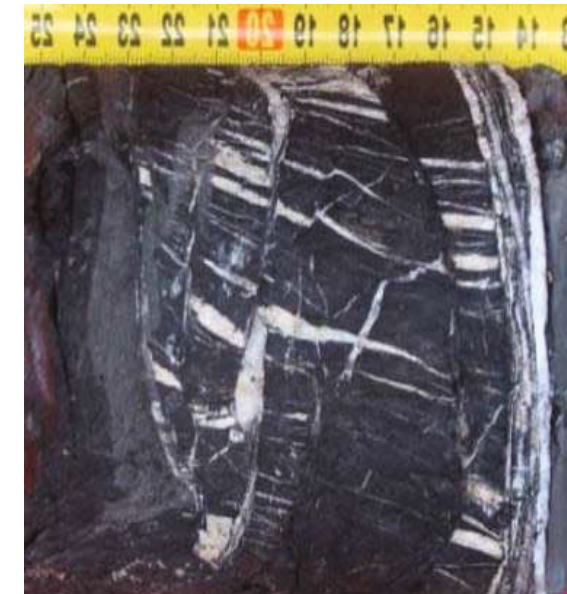

(a) High-angle structural fractures (JYA well, $3468.75 \mathrm{~m}$ )

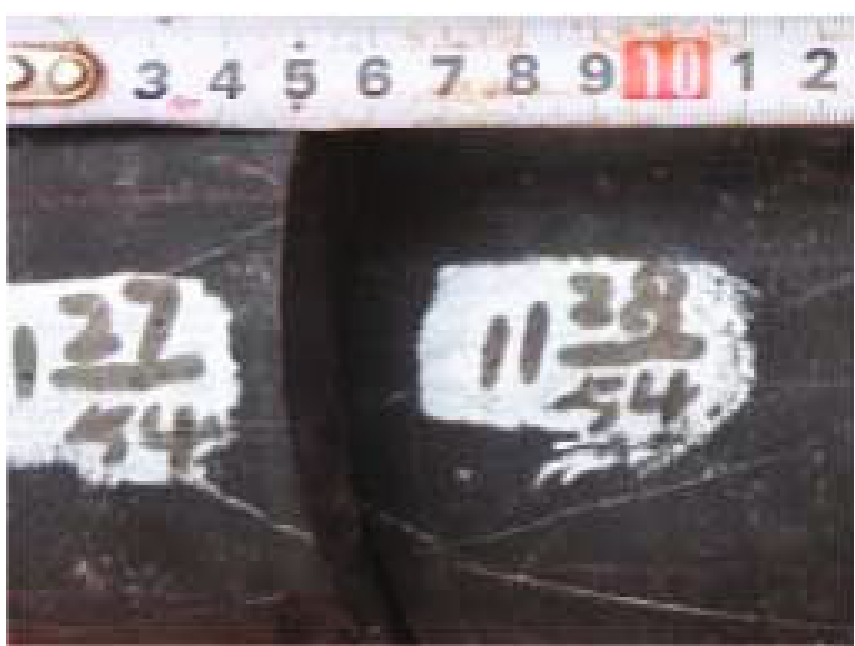

(b) En echelon fractures (JYC well, $2893.78 \mathrm{~m}$ )

FIgURE 3: Core image in the research area.

section observation, and analyze the fluid charging stages and formation pressure evolution process in the reservoir combined with fluid inclusion testing [17-21].

\subsection{Fluid Charging}

3.1.1. Characteristics of Fracture Veins. Veins in shale gas reservoirs are usually the product of multistage fluids related to faults and under pressure control [22]. According to the observation of cores from multiple coring wells, there are mainly high-angle structural fractures (Figure 3(a)), bedding slip fractures, interbedded foliation fractures, and some en echelon fractures (Figure 3(b)) in the core of Longmaxi formation. Further statistical analysis of the high angle fractures shows that the fracture width is mostly $0.11 \mathrm{~mm}$, and the widest fracture width is up to $3 \mathrm{~mm}$. The fracture density is mainly between 0.1 and $4 / \mathrm{m}$, and the calcite veins are filled along the bedding. Interlaminar fractures are widely developed, and the maximum fracture density can reach $420 / \mathrm{m}$. Through the observation of core fractures, it is found that the fractures of Longmaxi formation shale in southeast Chongqing are mostly filled with calcite and quartz to form veins. On the basis of macroscopic observation, microlithographic observation was carried out to determine the mineral composition and filling characteristics.

3.1.2. Inclusion Analysis. Fluid inclusion thermometry is the most convenient and widely used method to directly obtain the temperature, pressure, and salinity of fluid inclusion when it is captured. The samples of fluid inclusion analysis and test were taken from calcite and quartz veins filled in fractures of Longmaxi formation, including 15 pieces of JY1 well in Fuling block and 12 pieces of JY4 well. The rubbed veins and lining veins in the core were made into double-polished inclusion slices and observed under transmitted light and fluorescence. The test instrument was Olympus dual-channel fluorescence-transmission light microscope, and the temperature measurement error was \pm $0.1^{\circ} \mathrm{C}$. The homogenization temperature of gas-liquid twophase inclusions increased at a rate of $5^{\circ} \mathrm{C} / \mathrm{min}$ and $0.5^{\circ} \mathrm{C} /$ min before the phase boundary disappeared. The temperature of complete homogenization of the inclusions was observed and recorded, and the temperature was kept constant for $2 \mathrm{~min}$. Then, the temperature was cooled to observe the temperature of bubble appearance. The homogenization temperature of gas inclusions can be measured by rapidly cooling the inclusions to the phase transition point with liquid nitrogen, continuing to cool the inclusions to observe the change of bubbles, and then heating the inclusions to the homogeneous state, and recording the homogenization temperature. Abundant fluid inclusions were observed under the microscope. The organic inclusions of Longmaxi formation in the study area include two types: gas-liquid two-phase hydrocarbon inclusions emitting bright fluorescence (Figure 4(a)) and natural gas inclusions not emitting fluorescence (Figure 4(b)).

For gas-liquid two-phase inclusions (type I), at room temperature, obvious gas and liquid phases can be identified as the main characteristics, which are distributed in groups under the microscope. Most of the inclusions have a gasliquid ratio between $15 \%$ and $25 \%$, and a few have a gasliquid ratio between $25 \%$ and $90 \%$. The size of the inclusions varies greatly but generally not more than $15 \mu \mathrm{m}$. The morphology of the inclusions can be developed from irregular to negative crystal. Except for the quartz of well JY1, such inclusions are developed in calcite veins of JY1 well and JY4 well (Table 1). For pure gas inclusions (type II), it is characterized by a single gas phase (there may be a small amount of liquid phase which is difficult to be observed on the inclusions wall) at room temperature, and this type of inclusions is often symbiosis with type I inclusions in their occurrence. The size of inclusions varies greatly but generally not more than $10 \mu \mathrm{m}$. The shape is regular, mainly square, oval, etc. It is developed in quartz and calcite of filling veins in other wells. The homogenization temperature of 


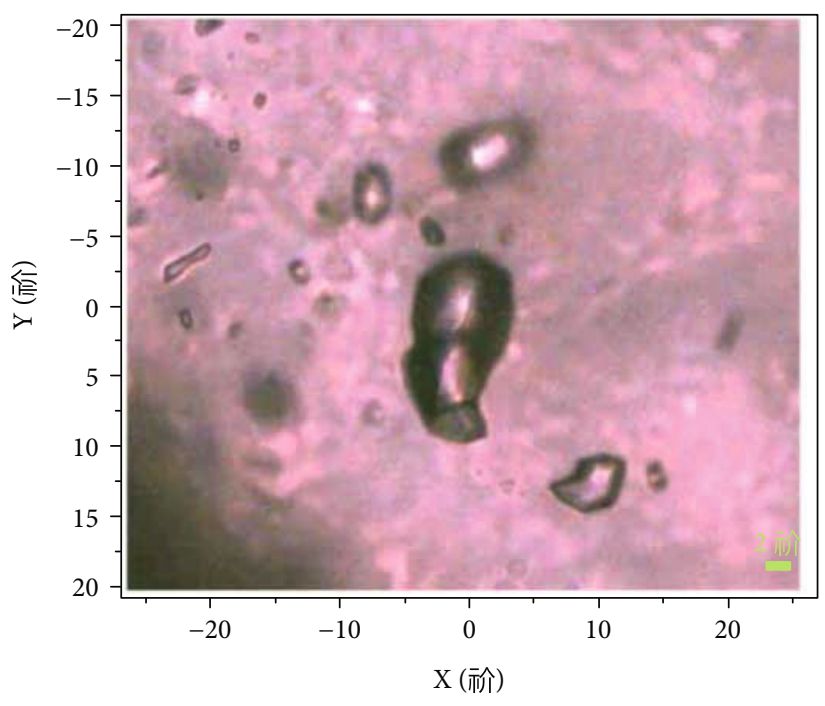

(a) Gas-liquid two-phase hydrocarbon inclusions

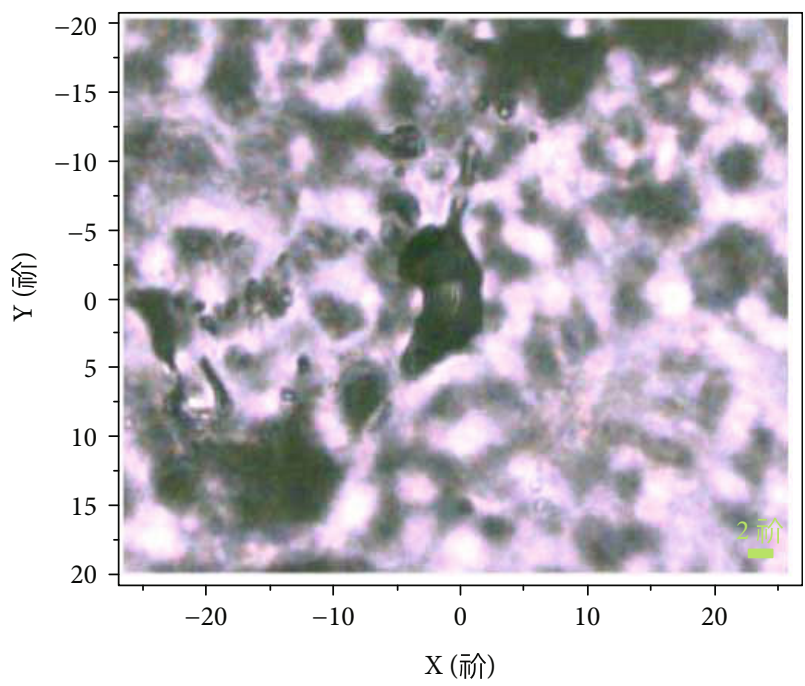

(b) Natural gas inclusions

FIgURE 4: Images of fluid inclusions.

TABLE 1: Details of the samples containing quartz and calcite veins selected for fluid inclusion analysis.

\begin{tabular}{lccc}
\hline Serial number & Well & Depth & Mineral samples \\
\hline 1 & JY1 & 2397.34 & Quartz \\
2 & JY1 & 2399.45 & Quartz \\
3 & JY1 & 2405.85 & Quartz \\
4 & JY1 & 2409.16 & Calcite \\
5 & JY4 & 2387.43 & Quartz \\
6 & JY4 & 2395.83 & Calcite \\
$\ldots$ & & & \\
\hline
\end{tabular}

gas-liquid inclusions in quartz and calcite of Longmaxi formation in JY1 well and JY4 well of the study area is mainly between $150^{\circ} \mathrm{C}$ and $240^{\circ} \mathrm{C}$, which has obvious two-stage filling characteristics. The peak temperature of the type $\mathrm{I}$ is $190^{\circ} \mathrm{C}$, and the peak temperature of the type II is $150^{\circ} \mathrm{C}$ (Figure 5).

3.1.3. Thermal Evolution History. Taking JY1 well as an example, the thermal maturation evolution history of Longmaxi formation source rocks in the study area is analyzed. Longmaxi formation began to enter the low maturity stage (Ro: $0.5 \%-0.7 \%$ ) in Silurian. Due to the influence of Caledonian tectonic movement, the thermal evolution rate of source rocks was relatively slow for a period of time. In the late Permian, the bottom of Longmaxi formation reached the medium maturity stage (Ro: $0.7 \%-1.3 \%$ ), and in the Triassic, the bottom of Longmaxi formation entered the maturity stage. In the late Triassic, the Longmaxi formation entered the high maturity stage (Ro: $1.3 \%-2.0 \%$ ). Although the strata were uplifted briefly, it did not affect the thermal evolution of source rocks too much. In the late Jurassic, the bottom of Longmaxi formation reached a high maturity stage (Ro $>2.0 \%)$; after entering the Late Cretaceous, the thermal evolution fully entered the overmature stage. In the late Cretaceous, the burial depth warming process

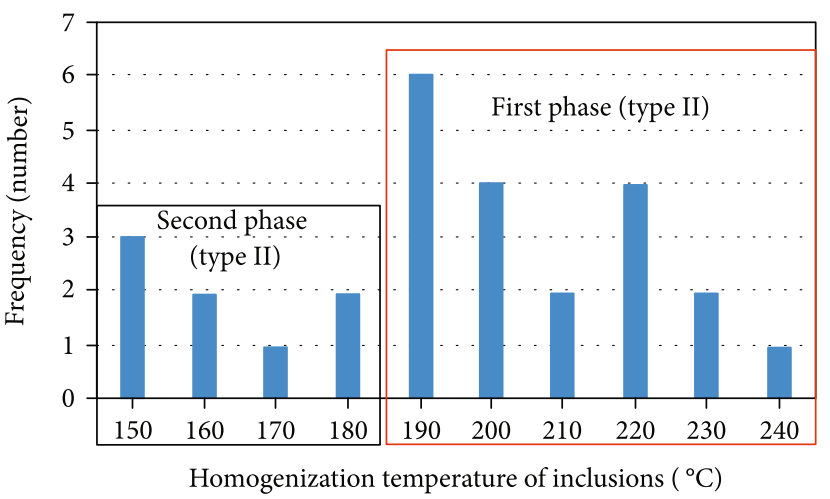

FIGURE 5: Distribution of homogenization temperature.

stopped, and the maturity of the Longmaxi formation remained above $3.0 \%$. Although the hydrocarbon fluid inclusions in the reservoir can not completely record the hydrocarbon accumulation process, the approximate time of hydrocarbon charging can be determined by the combination of burial history and thermal evolution history of source rock [23]. The results of inclusion homogenization temperature are projected onto the burial-thermal evolution history map (Figure 6), and it is determined that the Longmaxi formation reservoir in southeast Chongqing experienced two periods of gas charging. The first period of oil charging was in late Cretaceous, when a large amount of oil in the paleo-reservoir cracked and formed moisture gas into the reservoir. The second phase was mainly filled in the Paleocene, when the gas was charged with very high methane content, and a large number of gas inclusions were captured in the reservoir.

\subsection{Gas Reservoir Pressure Evolution}

3.2.1. Capture Pressure Calculation. The capture pressure of fluid inclusions in oil and gas reservoirs can be an important basis for understanding the paleo-pressure conditions 


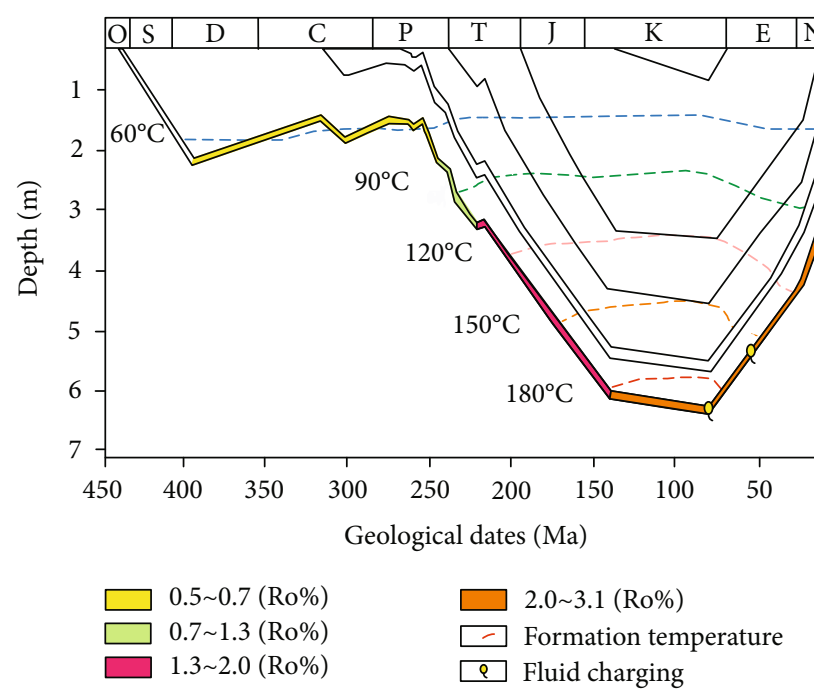

Figure 6: Thermal history and fluid charging history of Longmaxi formation [23].

of reservoir fluids in oil and gas reservoirs [24, 25]. Firstly, the microlaser Raman analysis of fluid inclusions is used to calculate the inclusion density when fluid inclusions were captured. LabRAM HR800 microlaser Raman spectrometer produced by HORIBA JY company in the United States was used for laser Raman spectrum analysis. Experimental parameters are as follows: temperature $25^{\circ} \mathrm{C}$, grating $1800 \mathrm{~cm}^{-1}$, Yag crystal frequency doubling solid state laser, wavelength $532 \mathrm{~nm}$, power $20 \mathrm{~mW}$, and linewidth < $0.1 \mathrm{~nm}$; the confocal effect of the spectrometer can reach the spatial resolution measurement of $0.1 \mu \mathrm{m}$ transverse and $0.3 \mu \mathrm{m}$ depth. The methane Raman scattering peak $v$ 1 displacement of methane inclusions fitted by $\mathrm{Lu}$ et al. has a good linear relationship with the density $\rho$ of methane inclusions:

$$
\rho=-5.17331 \times 10^{-5} D^{3}+5.53081 \times 10^{-4} D^{2}-3.51387 \times 10^{-2} D,
$$

where $\rho$ is the density of methane inclusions, $\mathrm{g} / \mathrm{cm}^{3}$. The correlation coefficient of $\rho$ and $D$ was $0.999 . D=v 1$ $-v 0 ; v 1$ is the corrected methane Raman scattering peak of measured methane inclusions. $v 0$ is the methane Raman scattering peak of methane inclusions when the pressure is close to 0 .

In this paper, the capture pressure of methane inclusions is calculated according to the equation of state established by Duan et al. [26].

$$
\begin{aligned}
Z=\frac{p V}{R T}= & \frac{p_{r} V_{r}}{T_{r}}=1+\frac{B}{V_{r}}+\frac{C}{V_{r}^{2}}+\frac{D}{V_{r}^{4}}+\frac{E}{V_{r}^{5}} \\
& +\frac{F}{V_{r}^{2}}\left(\beta+\frac{\gamma}{V_{r}^{2}}\right) \exp \left(-\frac{\gamma}{V_{r}^{2}}\right),
\end{aligned}
$$

TABLE 2: Details of the samples containing quartz and calcite veins selected for fluid inclusion analysis.

\begin{tabular}{lccccc}
\hline $\begin{array}{l}\text { Serial } \\
\text { number }\end{array}$ & Well & Depth & Density & $\begin{array}{c}\text { Capture } \\
\text { pressure }\end{array}$ & $\begin{array}{c}\text { Pressure } \\
\text { coefficient }\end{array}$ \\
\hline 1 & JY1 & 2397.34 & 0.278 & 132.27 & 2.10 \\
2 & JY1 & 2399.45 & 0.294 & 139.79 & 2.22 \\
3 & JY1 & 2405.85 & 0.266 & 126.45 & 2.01 \\
4 & JY1 & 2409.16 & 0.271 & 128.9 & 2.05 \\
5 & JY4 & 2387.43 & 0.222 & 105.64 & 1.68 \\
6 & JY4 & 2395.83 & 0.233 & 110.83 & 1.76 \\
$\ldots$ & & & & & \\
\hline
\end{tabular}

$$
\begin{gathered}
B=a_{1}+\frac{a_{2}}{T_{r}^{2}}+\frac{a_{3}}{T_{r}^{3}} \longrightarrow \longrightarrow=\frac{\alpha}{T_{r}^{3}}, \\
C=a_{4}+\frac{a_{5}}{T_{r}^{2}}+\frac{a_{6}}{T_{r}^{3}} \longrightarrow \longrightarrow P_{r}=\frac{P}{P_{c}}, \\
D=a_{7}+\frac{a_{8}}{T_{r}^{2}}+\frac{a_{9}}{T_{r}^{3}} \longrightarrow \longrightarrow T_{r}=\frac{T}{T_{c}}, \\
E=a_{10}+\frac{a_{11}}{T_{r}^{2}}+\frac{a_{12}}{T_{r}^{3}} \longrightarrow \longrightarrow V_{r}=\frac{P}{V_{c}}, \\
a_{1}=0.0872553928 ; a_{2}=-0.752599476 ; a_{3}=0.375419887 ; a_{4} \\
=0.0107291342 ; a_{5}=0.0054962636 ; a_{6}=-0.0184772802 ; a_{7} \\
=0.000318993183 ; a_{8}=0.000211079375 ; a_{9}=0.0000201682801 ; a_{10} \\
=-0.0000165606189 ; a_{11}=0.000119614546 ; a_{12}=-0.000108087289 ; \alpha \\
=0.0448262295 ; \beta=0.75397 ; \gamma=0.077167 .
\end{gathered}
$$

$p$ is the pressure, bar; $Z$ is the compression factor, dimensionless; $V$ is the molar volume, $\mathrm{dm}^{3} / \mathrm{mol}$ (it can be calculated from the density $\rho$ and molar mass of methane inclusions); $R$ is gas constant, the values: $8.314\left(\mathrm{~Pa} \cdot \mathrm{m}^{3}\right) /$ (K.mol); $p_{r}$ and $T_{r}$ are the comparative pressure and temperature, respectively, and their dimensions are $1 ; p_{c}$ and $T_{c}$ are critical pressure $(4.6 \mathrm{MPa})$ and critical temperature $(190.4 \mathrm{~K})$, respectively; $a_{i}, \alpha, \beta$, and $\gamma$ are derived from the fitting of the data points [27].

It is calculated that the main pressure of methane inclusions in the quartz veins of JY1 well is between 100 and $140 \mathrm{MPa}$ (Table 2) and the main pressure coefficient is between 1.8 and 2.2. The results indicate that the shale of Longmaxi formation in southeastern Chongqing has the characteristics of high temperature and ultrahigh pressure after fluid charging in the stage of maximum burial depth and early uplift, during the maximum burial depth stage and the initial uplift $[28,29]$. Therefore, the pressure evolution of Longmaxi formation in the study area is characterized by a short period of late uplift and pressure unloading, and a low pressure unloading intensity and current formation pressure coefficient remains at 1.55 , and it still is high-pressure gas reservoir (Table 3). 
TABLE 3: Gas reservoirs are classified by formation pressure coefficient (GB/T 26979-2011).

\begin{tabular}{lcccc}
\hline $\begin{array}{l}\text { Gas reservoir pressure } \\
\text { type }\end{array}$ & $\begin{array}{c}\text { Low pressure gas } \\
\text { reservoir }\end{array}$ & $\begin{array}{c}\text { Atmospheric pressure gas } \\
\text { reservoir }\end{array}$ & $\begin{array}{c}\text { High pressure gas } \\
\text { reservoir }\end{array}$ & $\begin{array}{c}\text { Ultrahigh pressure gas } \\
\text { reservoir }\end{array}$ \\
\hline Standard & $d_{p}<0.9$ & $0.9 \leq d_{p}<1.3$ & $1.3 \leq d_{p}<1.8$ & $d_{p} \geq 1.8$ \\
\hline
\end{tabular}

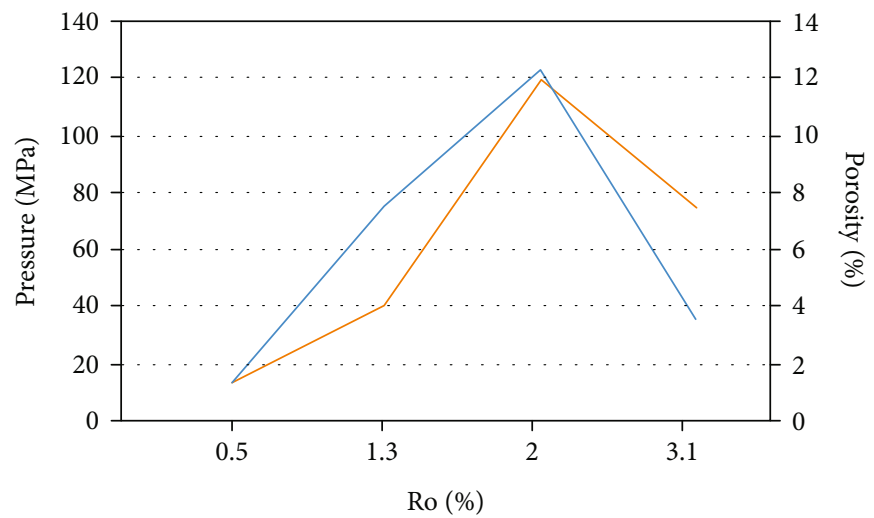

Figure 7: Relation graph of pressure and shale pore evolution.

3.2.2. Pressure Controls the Evolution of Reservoir Pores. The shale gas accumulation process of Longmaxi formation in southeast Chongqing area is very complicated, which is influenced by many factors such as structure, sedimentation, and diagenesis. The development degree of reservoir pores is not only closely related to various diagenesis but also controlled by hydrocarbon generation. In view of the particularity of shale gas resources, some scholars have proposed such accumulation theories as "sedimentary facies belt and enrichment rule," "tectonic type and tectonic action control of reservoir formation," "quartz resistance to the compaction and pore preservation," "reservoir fluid overpressure, compaction resistance," and constructed the research idea of "construction-destruction-remoulding" sequence. In order to study the influence of formation pressure on shale reservoir pore evolution, the vitrinite reflectance and porosity data points were projected onto the shale pore evolution model map (Figure 7) based on the shale pore evolution law and model published by Mastalerz at different maturity $[30,31]$. In general, the porosity of shale increases greatly with the increase of maturity, and the change trend of organic and inorganic pore sizes is consistent. Porosity reached a maximum of $11 \%$ at a vitrinite reflectance of about $2.0 \%$, then began to decline, and today, the reservoir porosity is around 3\%. The porosity of inorganic pores decreases with maturity, mainly due to the response of compaction, and the decrease of organic pores is probably due to the formation of asphalt blocking the pores. As the formation stops lifting, the tectonic movement flattens out, and porosity stops changing. At the same time, the original formation pressure data are also projected onto the model map, and it can be found that the pressure and porosity change with the vitrinite reflectance basically the same trend, so it can be considered that the development of reservoir porosity is affected by formation pressure to a certain extent.
Sufficient conditions, the pressure on the edge of the ultrahigh pressure deep within the study area and basin area, strong ability to resist the compaction of quartz mineral with shale rich in organic matter under the condition of ultrahigh pressure has good reservoir property; the upper powder sandstone compaction resistance is weak, even form the primary pore was hard to preserved, but is a good regional cap rocks. Since the beginning of Eocene, the southeast Chongqing area has been greatly affected by Himalayan movement, and the formation uplifted and pressure offloaded, which resulted in the densification of the reservoir and made it impossible for shale gas to be charged again.

\section{Results}

(1) There are mainly high-angle structural fractures, bedding slip fractures, interbedded foliation fractures, and some en echelon fractures in the core of Longmaxi formation. Among the high angle fractures show that the fracture width is mostly $0.11 \mathrm{~mm}$, and the widest fracture width is up to $3 \mathrm{~mm}$. The fracture density is mainly between $0.1 / \mathrm{m}$ and $4 / \mathrm{m}$, and the interlaminar fractures are widely developed, and the maximum fracture density can reach $420 / \mathrm{m}$

(2) Through the observation of core fractures, it is found that the fractures of Longmaxi formation shale in southeast Chongqing are mostly filled with calcite and quartz to form veins

(3) The organic inclusions of Longmaxi formation in the study area include two types: gas-liquid two-phase hydrocarbon inclusions (type I) emitting blue fluorescence and natural gas inclusions (type II) not emitting fluorescence. The peak temperature of the type $\mathrm{I}$ is $190^{\circ} \mathrm{C}$, and the peak temperature of the type II is $150^{\circ} \mathrm{C}$ 
(4) The main pressure of methane inclusion in the quartz veins of JY1 well is between 100 and $140 \mathrm{MPa}$, and the main paleo-pressure coefficient is between 1.8 and 2.2

\section{Discussions}

The ultrahigh pressure generated by fluid charging plays a very important role in shale gas accumulation. At present, it is generally believed that the ultrahigh pressure of gas reservoir is beneficial to the compaction resistance of shale pores and to the development of shale fractures and artificial fracturing in the later stage. This also leads to high formation energy, which allows drilling of high-yield gas wells. However, the current research degree is not deep enough to establish the quantitative relationship between "fluid charging - pressure relative increase rate - compaction rate - porosity," that means it is impossible to carry out quantitative calculation and research. In view of this problem, further theoretical and technical research should be carried out.

\section{Conclusions}

(1) Two types of inclusions were found in quartz and calcite veins of Longmaxi formation in the research area by microscopic observation. The first type (type I) is gas-liquid inclusions mixed with methane and brine, and the second type (type II) is pure gasphase inclusions with high methane content

(2) Combined with the results of thermal evolution analysis, the homogenization temperature of inclusions was put on the reservoir forming history map, and it was recognized that there were two periods of gas charging in Longmaxi formation in the study area. The first stage of charging took place in the Late Cretaceous with a burial depth of about $6,500 \mathrm{~m}$ and a formation temperature of $200^{\circ} \mathrm{C}$. The second phase of charging occurred in the Eocene when the stratum had begun to lift, with a burial depth of about $5400 \mathrm{~m}$ and a formation temperature of $150^{\circ} \mathrm{C}$

(3) According to the equation of state calculation, the capture pressure of methane inclusions (type II) in Longmaxi formation in the study area is $100 \mathrm{MPa} 140 \mathrm{MPa}$, and the main paleo-pressure coefficient is between 1.8 and 2.2. This indicates that the reservoir has reached ultrahigh pressure standards after charging

(4) The shale gas reservoir physical property of Longmaxi formation in the study area is not only controlled by tectonic movement and diagenesis but also influenced by pressure evolution. The ultrahigh pressure of reservoir pores formed during gas filling period inhibits compaction, which is beneficial to the maintenance of pore structure and reservoir physical property. The high quality shale gas reservoir in Longmaxi formation is formed when the ultrahigh pressure reservoir matches the upper densified cap rock

\section{Data Availability}

The data in the manuscript are all from laboratory measurements and references of previous research results and are expressed in the manuscript.

\section{Conflicts of Interest}

The authors declare that there is no conflict of interest regarding the publication of this paper.

\section{Acknowledgments}

This study is funded by the National Natural Science Foundation of China (No. 41902153), the Natural Science Foundation of Chongqing (No. cstc2020jcyj-msxmX0869), the Study on tracing oil migration based on nitrogen-, oxygen, and sulfur-containing compounds of crude oils (41902153), and the Control of shale gas content by quantitative characterization of fault activity (cstc2020jcyjmsxmX0869).

\section{References}

[1] T. Guo, "Evaluation of highly thermally mature shale-gas reservoirs in complex structural parts of the Sichuan Basin," Journal of Earth Science, vol. 24, no. 6, pp. 863-873, 2013.

[2] D. Dazhong, Z. Caineng, and Y. Hua, "Progress and prospects of shale gas exploration and development in China," Atca Petrolei Sinica, vol. 33, no. S1, pp. 107-114, 2012.

[3] L. Digang, G. Tonglou, and B. Lizeng, "Some progresses on studies of hydrocarbon generation and accumulation in marine sedimentary regions, southern China (part 3): controlling factors on the sedimentary facies and development of Paleozoic marine source rocks," Marine Origin Petroleum Geology, vol. 14, no. 2, 2009.

[4] S. Huanquan, Z. Dehua, and C. Xunyu, "Progress prospects in shale gas development of Sinopec," Petroleum Exploration, vol. 25, no. 2, pp. 14-26, 2020.

[5] M. A. Xinhua, J. Xie, R. Yong, and Y. Zhu, "Geological characteristics and high production control factors of shale gas reservoirs in Silurian Longmaxi Formation, southern Sichuan Basin, SW China," Petroleum Exploration and Development, vol. 47, no. 5, pp. 901-915, 2020.

[6] E. Mraz, M. Wolfgramm, I. Moeck, and K. Thuro, "Detailed fluid inclusion and stable isotope analysis on deep carbonates from the north alpine Foreland Basin to constrain Paleofluid evolution," Geofluids, vol. 2019, 23 pages, 2019.

[7] N. Haikuan, H. Wang, and H. Zhiliang, "Formation mechanism, distribution and exploration prospect of normal pressure shale gas reservoir: a case study of Wufeng FormationLongmaxi Formation in Sichuan Basin and its periphery," Acta Petrolei Sinica, vol. 40, no. 2, pp. 131-143, 2019.

[8] V. Dyja, C. Hibsch, A. Tarantola et al., "From deep to shallow fluid reservoirs: evolution of fluid sources during exhumation of the Sierra Almagrera, Betic Cordillera, Spain," Geofluids, vol. 16, no. 1, 2016.

[9] W. Zhigang, "Reservoir formation conditions and key efficient exploration \& development technologies for marine shale gasfields in Fuling area, South China," Acta Petrolei Sinica, vol. 40, no. 3, pp. 370-382, 2019. 
[10] L. Weixin, B. Fang, and Y. Lingjie, "Micro-pore structure and connectivity of the Silurian Longmaxi shales, southeastern Sichuan area," Petroleum Geology and Experiment, vol. 38, no. 4, pp. 453-459, 2016.

[11] S. E. Kesler, R. J. Bodnar, and T. P. Mernagh, "Role of fluid and melt inclusion studies in geologic research," Geofluids, vol. 13, no. 4, 2013.

[12] H. Xipeng, "Sweet spot evaluation system and enrichment and high yield influential factors of shale gas in Nanchuan area of eastern Sichuan Basin," Natural Gas Industry, vol. 41, no. 1, pp. 59-71, 2021.

[13] G. Yuqiao, C. Xiao, and Z. Peixian, "Pore characteristics and evolution of Wufeng-Longmaxi Fms shale gas reservoirs in the basin-margin transition zone of SE Chongqing," Natural Gas Industry, vol. 38, no. 12, pp. 15-25, 2018.

[14] Z. Shariatinia, S. Feiznia, A. Shafiei et al., "Multiple hydrocarbon charging events in Kuh-e-Mond oil field, Coastal Fars: evidence from biomarkers in oil inclusions," Geofluids, vol. 13, no. $4,2013$.

[15] Z. Wen, W. Hao, and X. Runcheng, "Characteristics and exploration potential of lower Paleozoic marine shale gas reservoir in middle-upper Yangtze area, China," Journal of Chengdu University of Technology (Science \& Technology Edition), vol. 40, no. 5, pp. 569-576, 2013.

[16] X. Binbin, T. Geer, and Y. Lingjie, "Trapping pressure of fluid inclusions and its significance in shale gas reservoirs, SouthEastern Sichuan Basin," Petroleum Geology and Experiment, vol. 38, no. 4, pp. 473-479, 2016.

[17] I. Wazir, M. Pagel, F. Tournier, E. Portier, and C. Renac, "Role of compressive tectonics on gas charging into the Ordovician sandstone reservoirs in the Sbaa Basin, Algeria: constrained by fluid inclusions and mineralogical data," Geofluids, vol. 14, no. 1, 2014.

[18] H. E. Gao Jian and Y. I. J. Sheng, "Discovery of high density methane inclusions in Jiaoshiba shale gas field and its significance. Oil \& gas," Geology, vol. 36, no. 3, pp. 472-480, 2015.

[19] G. Jian, Paleo-Temperature and Pressure and Origin of PaleoFluid of Fracture Veins in the Wufeng-Longmaxi Shales of Yudong Area [D], China University of Geosciences, Wuhan, 2018.

[20] L. Wen, H. Sheng, and Z. Baiqiao, "Characteristics of paleotemperature and paleo-pressure of fluid inclusions in shale composite veins of Longmaxi Formation at the western margin of Jiaoshiba anticline," Acta Petrolei Sinica, vol. 39, no. 4, pp. 402-415, 2018.

[21] R. Deng, C. Chen, S. Shi, and Y. Wang, "Fluid phase simulation and evolution of a condensate gas reservoir in the Tazhong Uplift, Tarim Basin,” Geofluids, vol. 2019, 15 pages, 2019.

[22] L. Yan, Y. Zheng, C. Wang, and P. Yu, "Application of Fluid Inclusions Methodology in the Shale Gas Study: A Review," Journal of Geomechanics, vol. 25, no. S1, pp. 103-107, 2019.

[23] J. Wu, C. Xuezhong, and L. Wenping, "Fluid Activity and Pressure Evolution Process of Wufeng-Longmaxi Shales, Southern Sichuan Basin," Earth Science, vol. 12, no. 10, pp. 1-17, 2021.

[24] Z. Meizhen, S. Weijun, and Z. Zhirong, "Laser Raman microscope and its application in geology," Petroleum Geology \& Experiment, vol. 30, no. 3, pp. 307-310, 2008.

[25] L. Ruobing, "Analyses of influences on shale reservoirs of Wufeng-Longmaxi Formation by overpressure in the southeastern part of Sichuan Basin," Acta Sedimentologica Sinica, vol. 33, no. 4, pp. 817-827, 2015.
[26] D. Zhenhao and S. Mao, "A Thermodynamic Model for Calculating Methane Solubility, Density and Gas Phase Composition of Methane-Bearing Aqueous Fluids from 273 to $523 \mathrm{~K}$ and from 1 to 2000 bar," Geochimica et Cosmochimica Acta, vol. 70, no. 13, pp. 3369-3386, 2006.

[27] D. Zhenhao, N. Moller, and J. H. Weare, "An Equation of State for the CH4-CO2-H2O System: I. Pure Systems from 0 to $1000^{\circ} \mathrm{C}$ and 0 to 8000 bar," Geochimica et Cosmochimica Acta, vol. 56, no. 7, pp. 2605-2617, 1992.

[28] L. Honglin, W. Hongyan, and F. Chaohe, "The formation mechanism of over-pressure reservoir and target screening index of the marine shale in the South China," Earth Science Frontiers, vol. 23, no. 2, pp. 48-54, 2016.

[29] H. A. SHELDON and A. ORD, "Evolution of porosity, permeability and fluid pressure in dilatant faults post-failure: implications for fluid flow and mineralization," Geofluids, vol. 5, no. 4, 2005.

[30] M. Mastalerz, A. Schimmelmann, A. Drobniak, and Y. Chen, "Porosity of Devonian and Mississippian New Albany shale across a maturation gradient: insights from organic petrology, gas adsorption, and mercury intrusion," AAPG Bulletin, vol. 97, no. 10, pp. 1621-1643, 2013.

[31] H. Degao, W. Yunqiang, and F. Dongliang, "Pore characteristics and evolution model of shale in Wufeng-Longmaxi Formation in Sichuan Basin," Periodical of ocean university of china, vol. 51, no. 10, pp. 80-88, 2021. 